\title{
O FANTASMA E O REAL: SOBRE A DESIGUALDADE ENTRE OS SEXOS
}

\author{
Márcia Aparecida Zucchi* \\ Tânia Coelho dos Santos**
}

\section{RESUMO}

Neste breve artigo, as autoras retomam a afirmação freudiana de que "a anatomia é o destino” à luz do Seminário 20 de Lacan e das proposiçōes de Jacques Alain Miller sobre este tema. O real impossível - a inexistência da relação sexual - não se manifesta do mesmo modo para homens e mulheres, o que exige reconsiderar o valor das consequiências psíquicas da diferença anatômica entre os sexos. Em oposição a um processo de identificação que se estruture dispensando o sexo corporal, as autoras pretendem demonstrar que a diferença sexual é o que há de mais real no processo de subjetivação.

Palavras-chave: real, diferença sexual, identidade

\section{Abstract}

\section{PHANTASM AND REAL: ABOUT THE UNLIKENESS BETWEEN THE SEXES}

In this brief paper the authors retake the freudian statement "anatomy is the destiny" in the light of the concepts of Lacan's 20th Seminar and Jacques-Alain Miller's proposals about this subject. The real impossible - the nonexistence of the sexual relationship - isn't experienced in the same way in men and women. Then it is necessary to reconsider the value of psychic consequences of the anatomic difference between sexes. In opposition to an identification process

* Doutora em Teoria Psicanalítica UFRJ; Mestre em Ciências da Saúde na Fiocruz; Aderente à Escola Brasileira de Psicanálise; Pesquisadora do Núcleo Sephora de Pesquisa sobre o moderno e o contemporâneo.

** Doutora em Psicologia Clínica pela PUC/RJ; Pós-doc no Département de Psychanaltryse de Paris VIII; Professora Associada do programa de PósGraduação em Teoria Psicanalítica / UFRJ; Psicanalista, Membro da Escola Brasileira de Psicanálise e da Associação Mundial de Psicanálise. 
in what the sexual body is not determinant, the authors intend to show that the sexual difference is what is the very real in the subjetivation process.

Keywords: real, difference between sexes, identity

\section{A ATUalidade EM Debate}

Convidamos nosso leitor a contemplar os seguintes excertos de um filme recente chamado "Todas as cores do amor". O título recorda esse conhecido trecho da música de Milton Nascimento e Caetano Veloso "qualquer maneira de amor vale a pena, qualquer maneira de amor vale amar". Essa perspectiva sobre o amor e a sexualidade expandiu-se na cultura depois dos movimentos pela liberação da sexualidade que sobrevieram no rastro dos acontecimentos de maio de 1968. A psicanálise precisa atualizar-se em conformidade com as mudanças da civilização. Como o conhecido psicanalista lacaniano costuma relembrar, "não há clínica do sujeito sem clínica da civilização" (Miller e Milner, 2004: 46). Entretanto, os fundamentos da teoria e da clínica psicanalítica do sujeito e de suas relações com a civilização nem sempre estarão em consonância com as ideologias e representações sociais. Hoje, quando os movimentos sociais nos impóem a representação de que a sexualidade psíquica e o sexo anatômico não guardam entre si nenhuma relação, precisamos dizer o que nossa experiência como analistas nos ensina sobre a diferença sexual.

No filme mencionado acima, os indivíduos mantêm relações amorosas e relaçóes sexuais com parceiros de ambos os sexos, segundo a fluidez própria aos laços contemporâneos (Bauman, 2004). A rapidez das mudanças e a, pelo menos aparente, pouca densidade dos afetos que as acompanham criam uma atmosfera propícia à crença de que para um sujeito humano qualquer tipo de relação amorosa é igualmente desejável. Talvez algumas sejam mais satisfatórias do que outras, mas o sexo do parceiro é relativamente indiferente. $\mathrm{O}$ filme em questão não nos apresenta, entretanto, uma idéia enganosa de que haveria encontro e complementaridade entre indivíduos, seja do mesmo sexo, seja de sexos diferentes. Nenhuma dessas relações é inteiramente satisfatória. Todas exibem, no fracasso, sua evidente precariedade. $\mathrm{O}$ que nos chama a atenção, enquanto pesquisadores em psicanálise, é que a grande variabilidade de parceiros não esconde a mesma e invariável monotonia no plano da satisfação amorosa. Nenhuma relação merece o privilégio de se destacar de qualquer outra. A moral sexual civilizada contemporânea reza que quanto mais liberdade de trocar de parceiro, ou de sexo, maior a convicção de que todas as relações são iguais, um só e o mesmo desenlace. 
Observem agora as seguintes cenas do cotidiano na cidade:

Cena 1: dois rapazes estrangeiros, bem musculosos e saudáveis, vestidos de forma esportiva porém denotando um nível socioeconômico médio ou médioalto, passeiam de mãos dadas por uma rua de comércio de Copacabana. As reações despertadas ressaltam em uníssono a desaprovação. Porteiros e madames, domésticas e empresários, todos estão de acordo em rejeitar o que lhes parece um despudor. Ora um riso, ora um olhar de espanto, até a exclamação "Que pouca vergonha, é o fim do mundo!".

Cena dois: duas jovens entre 13 e 15 anos, cujos trajes sugerem que pertencem à classe média, brasileira, passeiam de mãos dadas pelo calçadão de Copacabana compartilhando olhares, carícias e também o auricular de um Ipod. As reações são menos retumbantes do que na cena 1 . São os homens que basicamente olham, expressando um misto de crítica e de um interesse talvez sexual.

A homossexualidade ainda choca a sociedade? Se nos baseamos nas observaçôes de cenas cotidianas como as que relatamos acima, a resposta parece ser sim. A escolha homossexual, no entanto, não parece ter mais, nos dias de hoje, um caráter contestatório da "norma sexual". A homossexualidade explícita não parece guardar qualquer resquício de um ato político libertário, pelo qual novas possibilidades de felicidade e de amor se afirmariam. O que nos chama a atenção nas duas cenas e no filme mencionado é especialmente a diferença na resposta dos atores sociais à homossexualidade em homens e mulheres. Ela contrasta com o pano de fundo que o filme estabelece, onde reina uma aposta de que o objeto de amor é indiferente, que pretende legitimar as escolhas homossexuais de objeto.

A aplicação da psicanálise como instrumento de leitura dos movimentos da sociedade exige sempre que se demarque sua diferença de ponto de vista com o pensamento sociológico. A psicanálise se orienta por um compromisso ético com a clínica sob transferência. Estão em jogo as ficções do inconsciente, o que nos impõe uma grande diferença quanto à perspectiva adotada pelos atores sociais. A psicanálise toma a diferença sexual como um dado da estrutura da experiência do ser falante. Desde o nascimento se é menino ou menina. Esse destino está escrito no corpo, é nomeado na linguagem e seus efeitos sobre as identificações e sobre a escolha de objeto não permitem que essas escolhas sejam livres. $\mathrm{O}$ ser falante repete, não escolhe livremente entre ser homem ou mulher. Segundo dizia Freud, “a anatomia é o destino" (Freud, 1924/1976: 222). Lacan, por sua vez, com o conceito de fantasma, nos ensinou a abordar a "escolha forçada" em jogo na vida, na morte e na sexualidade. Ao ser falante cabe a liberdade de responsabilizar-se por sua vida, sua morte e por seu sexo. A orientação lacaniana nos ensina que o real é o impossível. O que não se pode educar, governar ou curar revela que há 
algo mais em jogo na vida psíquica do que o inconsciente. O Real é essa dimensão que escapa às nossas ficções e se levanta contra nossas pretensões a uma liberdade infinita em nossas "invençôes" (Miller, 1998).

Este breve artigo pretende tratar da sexualidade de um ponto de vista francamente contracultural e não pós-moderno. Nosso esforço será o de atualizar o dito atribuído a Napoleão Bonaparte e recuperado por Freud de que "a anatomia é o destino" (Freud, 1924/1976) à luz do Seminário 20 de Jacques Lacan (Lacan, 1972-1973/1985).

Como podemos entender esta afirmação freudiana que já foi tanto aceita quanto contestada? Sem dúvida há várias leituras desse aspecto. Os psicanalistas da tradição freudiana afirmam que o sexo anatômico dirige a escolha normal do objeto sexual, a heterossexual. Depois da década de 70, muitos psicanalistas descartaram essa afirmação freudiana como um equívoco próprio à sua formação numa cultura vitoriana. A primeira leitura orientou boa parte da escola inglesa que tomou a organização genital infantil como uma evolução do polimorfismo pulsional em direção a essa normalização, cujo ápice seria a primazia genital. A escolha do objeto evoluiria conforme a organização das pulsões parciais, do mais periférico do corpo aos órgãos genitais. Leitura que supunha, portanto, o objeto adequado para cada sexo. Evidentemente, nesta leitura a homossexualidade pode ser uma neurose ou uma perversão. Já no outro extremo, sem dúvida fortemente influenciado pela leitura lacaniana de Freud, não haveria nenhum ponto de chegada no desenvolvimento pulsional. Contra o ponto de vista de Karl Abraham, para quem as pulsóes tendiam a se organizar orientadas pelos ideais de amadurecimento, autenticidade e reciprocidade, Lacan estabelece um novo ponto de vista baseado na distinção entre o real, o imaginário e o simbólico.

O conceito de objeto em Lacan precisa ser articulado segundo os seis paradigmas do gozo (Miller, 2000) tal como são desenvolvidos ao longo de seu ensino. Considerando-se os desdobramentos epistemológicos que Miller vem fazendo quanto a esse ensino, estabelecendo a existência de pelo menos três níveis, é importante destacar que as relaçōes entre corpo e linguagem variam significativamente nestes três momentos. Inicialmente, a análise lacaniana do inconsciente esteve enfaticamente orientada pela demonstração de sua dependência da linguagem. Trata-se, neste primeiro ensino, do período no qual Lacan buscará retomar a descoberta freudiana, a partir das bases que lhe pareciam efetivamente originais, ou seja, das relaçóes que Freud havia descoberto entre a sexualidade e a linguagem. Neste período, a prevalência é da estrutura de linguagem e o corpo era mortificado pelo significante. $\mathrm{O}$ corpo, nessa vertente é uma imagem constituída por meio do significante. $\mathrm{O}$ encontro com a imagem no espelho precipita na criança 
uma reação de júbilo, pois, por meio dela, experimenta seu corpo unificado. $\mathrm{O}$ objeto então se divide entre a imagem do outro unificado (o semelhante) e o objeto causa do desejo (a libido), que não tem imagem especular. Porque o Outro enquanto suporte da fala e da linguagem não pode se reduzir à imagem do espelho, o encontro com a imagem especular (o semelhante) deixa como resto o objeto sem imagem, a causa do desejo. É esse outro objeto que Lacan formaliza no segundo momento do seu ensino. À vertente estritamente imaginária do objeto (de semelhante) e ao caráter simbólico (vazio) se acrescentam os objetos parciais que vêm suplementar esse vazio. O corpo surge numa outra dimensão, o da pulsação temporal, do movimento de abre e fecha da presença e da ausência do objeto nas zonas erógenas. Destaca-se assim que o inconsciente estruturado como a linguagem em sua pulsão temporal tem uma outra face, a do gozo que se apresenta num movimento homólogo, como surgimento e perda do objeto nas zonas erógenas. $\mathrm{O}$ conceito de fantasma ( $\$$ à a) articula as duas vertentes do inconsciente. $\mathrm{O}$ sujeito na linguagem é $\$$, identificado aos significantes do Outro. No nível do gozo do corpo, ele é tão somente um objeto parcial para o desejo do Outro. O fantasma é o conceito que permite abordar as duas vertentes do inconsciente em jogo na experiência analítica: a do sentido a ser decifrado e a do gozo a ser modificado.

Neste percurso necessitaríamos incluir ainda alguns desdobramentos quanto à questão do corpo no último ensino de Lacan. Diríamos, de modo bastante sucinto, que Lacan provoca, a partir do Seminário 20, uma radicalização dos fundamentos da subjetividade ancorando-os no real do gozo. Em seu primeiro ensino o sujeito era um efeito metafórico do significante do Nome do pai. O sujeito era a própria significação fálica $(\$)$, que se produzia quando o significante paterno substituía a criança/falo, como objeto do desejo da mãe. Em seu segundo ensino, como demonstramos, o sujeito se define por meio do fantasma ( $\$$ à a). Ele não é mais apenas a significação fálica (\$), mas também objeto de gozo do Outro. Em seu último ensino Lacan nomeia o sujeito como ser falante. Sujeito e gozo do fantasma ( $\$$ à a) são articulados, nessa nova teorização, como insígnia $\left(S_{1}, a\right)$. $\mathrm{O}$ ser falante é um corpo vivo atravessado pela linguagem. A linguagem, a partir do Seminário 20, é tratada não mais como o que mortifica o gozo, mas como o que o vivifica. A linguagem aparelha o gozo do corpo, isto é, aparelha o sujeito para gozar do corpo. O real como impossível é encarnado na diferença entre os sexos. Não há relação sexual. Não há equivalência entre os sexos. No Seminário 23, Lacan nos apresenta os três registros, real, imaginário e simbólico, como peças avulsas. Indica que uma articulação entre a letra (fora, ou anterior à cadeia) e o corpo confere a consistência elementar do falante, prévia ou ex-sistente a qualquer 
amarração entre os registros do simbólico, do imaginário e do real (Lacan, 197576/2005: 65). É preciso um quarto nó, o Nome do Pai, para que esses registros sejam enlaçados uns aos outros. Em seu último ensino, Lacan reafirma que o pai é aquele que confere peso sexual às palavras. Não há responsabilidade senão sexual. Do Nome do Pai depende um certo saber-fazer com o que resulta na articulação entre os registros. "On n'est responsable que dans la mesure de son savoirfaire” (Lacan, 1975-1976/2005: 61). Isso se esclarece conforme se segue: uma mulher é para um homem um sinthoma e um homem é para uma mulher algo pior que um sintoma, uma aflição.

O real impossível, a inexistência da relação sexual, como se pode concluir, não se manifesta do mesmo modo para homens e mulheres. A consideração do corpo enquanto vivo nos exige reconsiderar o valor das conseqüências psíquicas da diferença anatômica entre os sexos.

\section{EXCERTOS DE UMA TEORIA QUEER SOBRE A SEXUALIDADE}

Uma das correntes teóricas que buscam descentrar o modo de conhecimento ocidental pós-moderno, sustentado nas oposições masculino/feminino e heterossexualidade/homossexualidade, são as chamadas teorias "queer". Trata-se de uma corrente fortemente desenvolvida nos anos 90, na esteira do pós-estruturalismo e que, nos mais diferentes campos, visa servir-se da sexualidade desviante como método para repensar os padrões culturais. Trata-se, sem dúvida, de um movimento político.

No dicionário eletrônico Michaelis, encontramos as seguintes definições para o termo "queer: adjetivo (1) esquisito, ridículo, fantástico, estranho. (2) adoentado. (3) substantivo homossexual, veado, bicha louca. verbo (1) estragar, arruinar. (2) embaraçar, desconcertar. (3) colocar-se em posição embaraçosa. He is in queer street /ele está com dívidas até o pescoço" (Michaelis, 2006).

O termo conjuga aspectos culturalmente considerados positivos e negativos. Todavia, é evidente que o que se destaca em sua significação é sua oposição à norma e à boa forma. Como esclarece Louro:

Queer é tudo isso: é estranho, raro, esquisito. Queer é também o sujeito da sexualidade desviante - homossexuais, bissexuais, transexuais, travestis, drags. É o excêntrico que não deseja ser "tolerado". Queer é um jeito de pensar e de ser que não aspira o centro nem o quer como referência; um jeito de pensar e de ser que desafia as normas regulatórias da sociedade, que assume o desconforto da ambigüidade, do "entre lugares", do indecidível. Queer é um corpo estranho, que incomoda perturba, provoca, fascina (Louro, 2004: 7-8). 
As teorias queer consideram que a heterossexualidade é apenas uma norma, uma instituição cultural, e não uma dimensão anatômica. Seu método de análise é desconstrutivo e descentralizador, pretendendo uma ruptura epistemológica com as formas de conhecimento dominantes na cultura, onde a binariedade sexual repartiria quase todos os modos de apreensão da realidade. Esses autores visam

provocar um jeito novo de conhecer e também pretendem apontar outros alvos de conhecimento. [...] A oposição binária heterossexualidade/homossexualidade ganha centralidade nas análises desses autores, uma vez que entendem ser essa uma oposição que articula as práticas sociais e culturais, articula o conhecimento e o poder, contribuindo assim para a produção de sujeitos. A homossexualidade é analisada como parte de um regime de poder/saber (mais do que como uma identidade social minoritária) (Louro, 2004: 59-60).

Isto conduz a uma posição conceitual fundamental: a sexualidade não define uma identidade. Trata-se de uma política pós-identitária onde o foco é a cultura e suas estruturas discursivas e não a identidade (Louro, 2004: 59-60). As teorias queer se desenvolveram com base em Michel Foucault, Jacques Derrida e até mesmo Jacques Lacan. Sua abordagem da relação entre o saber e o poder sobre a sexualidade se baseia em Foucault. Deve a Derrida a idéia de que o pensamento ocidental opera por binarismos, elegendo os elementos centrais e estabelecendo a partir daí o seu "outro" ou seu oposto subordinado ou inferior, o que exigiria sempre uma desconstrução do discurso ordenador. Tomam de empréstimo a Lacan a noção de que o sujeito se constitui no campo do Outro, logo, não há nenhuma identidade sexual, somente identificaçôes (Louro, 2004: 39-42). Como não ignoram que a relação sexual não existe e que o Outro é inconsistente, acreditam que os corpos são afetados, independentemente da diferença anatômica, por qualquer forma de gozo.

Partindo das proposiçôes de Louro a respeito das relações entre a sexualidade e a educação, verifica-se que a construção da seqüência sexo-gênero-sexualidade é percebida como um ato cultural, determinado inicialmente por uma nomeação (“é menino!" ou “é menina!"), mas reiterado constantemente nas mais diversas práticas sociais. Todavia, há sujeitos que seguem desviantes em relação a estas normas, rompendo estas seqüências pré-estabelecidas. Como afirma a autora: "Efeitos das instituições, dos discursos e das práticas, o gênero e a sexualidade guardam a inconstância de tudo o que é histórico e cultural; por isso, às vezes escapam e deslizam" (Louro, 2004: 17).

Louro se utiliza da metáfora da viagem e do cruzamento de fronteiras para descrever os sujeitos que escapam à determinação cultural sexo-gênero-sexualida- 
de, afirmando o caráter eminentemente político da ultrapassagem dessas fronteiras. Uma conduta desviante de um sujeito tende a influenciar a de seus contemporâneos no sentido de ampliarem suas possibilidades de ser e viver (Louro, 2004: 23). A autora faz uma interessante análise da evolução dos movimentos políticos de inclusão social da homossexualidade e dos sujeitos homossexuais ao longo das três últimas décadas, quando o segredo e a segregação foram sendo progressivamente substituídos pela tolerância e pela convivência com as diferentes modalidades de gozo do corpo. Trata-se inicialmente de uma política de reforço identitário, da construção da comunidade homossexual, que passa, depois dos anos 80 , a uma política pós-identitária, onde o que conta é a desconstrução de uma concepção de sexualidade sustentada exclusivamente em duas binariedades: masculino/feminino e heterossexual/homossexual, a fim de que se passe a incluir e legitimar um maior número de práticas e prazeres sexuais (Louro, 2004: 29-38).

A autora reconhece, porém, que nem todos os sujeitos que desviam sua sexualidade, fazem-no decididos a um ato político subversivo'.

Cabe notar, ainda, que a autora se refere à inconstância do gênero e da sexualidade sem negar a materialidade anatômica da diferença entre os sexos. Ressalta, porém, que o que interessa na discussão das relaçóes entre a sexualidade e o dado corporal é antes de tudo como o corpo se presta a transformaçôes histórico culturais, ou, em suas próprias palavras: "o que se enfatiza são os processos e as práticas discursivas que fazem com que aspectos dos corpos se convertam em definidores de gênero e de sexualidade e, como conseqüência, acabem por se converter em definidores dos sujeitos" ( Louro, 2004: 80).

\section{O PARCEIRO LIBIDINAL COMO PARCEIRO-SINTOMA}

No seminário "O Outro que não existe e seus comitês de ética", Miller (19961997/2005) começa a esboçar uma teoria complementar à teoria do sujeito, a teoria do parceiro. O parceiro é aquele com quem o sujeito joga sua partida, é o que não lhe permite manter-se homeostático (Miller, 1996-1997/2005: 284). Essa parceria se revela em vários níveis que vão desde o parceiro-imagem até o parceiro-sintoma. A incompletude do sujeito, dada a prematuridade do humano, implica uma rivalidade entre o sujeito e sua imagem. O narcisismo, tal como Lacan formalizou esse conceito freudiano, é o estádio do espelho onde a imagem de si se constitui a partir da imago do Outro. Há, portanto, uma rivalidade imaginária do sujeito com sua imagem no espelho. Lacan distinguia, nesse momento do seu ensino, dois eixos entrecruzados da constituição do sujeito: o eixo simbólico ( $\mathrm{S}$ A) e o eixo imaginário (a - a’) (Miller, 1996-1997/2005: 290). Há os parceiros 
simbólicos do sujeito, aqueles que lhe permitem resolver o impasse imaginário do espelho. O parceiro simbólico por excelência é o falo enquanto significante. $\mathrm{O}$ falo simbólico estabelece a diferença entre o outro imaginário e o Outro simbólico. O primeiro é o semelhante, aquele que pode enganar, e o segundo é o Outro como lugar da verdade. Todavia, como aponta Miller, o parceiro falo simbólico é complexo, pois não se trata exclusivamente do Outro garante da verdade. $\mathrm{O} \mathrm{Ou}$ tro que a análise desvela na linguagem é um Outro desejante, o que faz com que a parceria simbólica seja desdobrada em parceiro-falo e parceiro do amor: "não somente como parceiro da boa-fé em relação às tapeações imaginárias, mas também como um parceiro complexo que se apresenta com uma dialética diversificada segundo os sexos" (Miller, 1996-1997/2005: 292-293).

O parceiro essencial, embora Miller se refira a "uma dialética diversificada segundo os sexos", parece ser o apenas o objeto $a$ do fantasma ( $\$$ à a). O objeto $a$ pode ser uma imagem, um pedaço extraído ao corpo do sujeito ou do Outro. Ele vale como ponto de gozo que resulta da indiferenciação entre o sujeito e o Outro. O parceiro essencial do sujeito, de acordo com Miller, é algo de seu gozo. Um parceiro auto-erótico. A partir do Seminário 20, Lacan elaborará esta relação do sujeito ao seu gozo distinguindo, de acordo com as fórmulas da sexuação, o modo masculino e o modo feminino de fazer suplência à relação sexual que não existe. Não há equivalência entre o gozo feminino e o masculino. Eles não são idênticos nem complementares. Essa dissimetria designa aos homens o gozo com o fantasma (\$ à a). Do lado feminino, a mulher se interessa em receber do homem o filho como o equivalente do falo que ela não tem e isso a identifica. Lacan, nesse seminário, vai além de Freud quando esclarece "o que quer verdadeiramente uma mulher”. Se ela quer o falo, é para, por meio dele, aceder ao discurso amoroso [S (A barrado)]. De acordo com Miller, para os homens e as mulheres:

Trata-se de uma nova doutrina do amor em que este não passa apenas pelo narcisismo. $\mathrm{O}$ amor passa pela existência do inconsciente, o que supõe que o sujeito perceba o tipo de saber que nele responde à não-relação sexual, ou seja, supõe a percepção, no parceiro, do sintoma que ele elaborou em razão da nãorelação sexual (Miller, 1996-1997/2005: 295).

O parceiro libidinal é, assim, um cenário privilegiado da parceria subjetiva e, mais especificamente, sintomática. Conforme nos indica o próprio Miller, na perspectiva analítica, frente ao impossível da relação sexual, cria-se a necessidade do sintoma e a contingência da relação entre o gozo e o Outro, isto é, o amor. 
Nesse contexto: "o amor quer dizer que a relação com o Outro não é estabelecida por qualquer instinto. Ela não é direta, e sim mediada pelo sintoma. Eis por que Lacan pôde definir o amor como o encontro, no parceiro, dos sintomas, dos afetos, de tudo o que nele e em cada um marca o rastro de seu exílio da relação sexual (Miller, 1996-1997/2005: 258).

$\mathrm{Na}$ perspectiva do sintoma como mensagem escrita no fantasma, o Outro libidinal é, em geral, aquele onde o sujeito reencontra, sob a forma de objeto, sua própria posição de gozo. Já na perspectiva do sintoma como resposta real à inexistência da relação sexual, o parceiro libidinal é aquele que encarnaria o mais de gozar do sujeito.

Resta-nos tratar a questão do sintoma como resposta real frente à castração. Como se constrói o sintoma para homens e mulheres.

\section{O SEXO ENTRE O NOMINALISMO E O REALISMO}

Este subtítulo faz explicita alusão ao texto de Eric Laurent, $O$ nome do pai entre realismo e nominalismo (Laurent, 2005). Neste artigo, o autor nos apresenta um panorama das discussões atuais sobre as práticas sexuais e seus corolários (procriação por ectogênese, novos contratos de casamento, novas organizações familiares e etc). Mostra que o debate gira em torno da constatação de que as práticas técnico-jurídicas expressam claramente o arbitrário da nomeação, ampliando indefinidamente os semblantes quanto ao sexo e à procriação em contraste com a busca sôfrega por um fundamento "natural".

Laurent segue sua análise, avaliando a posição do pai ao longo da teorização psicanalítica de Freud e Lacan. Face ao nominalismo que marca o discurso do mestre moderno, Freud foi criticado por colocar o pai na origem do sujeito bem como na base de sua antropologia. Dito de outro modo, Freud foi criticado por colocar numa relação hierárquica e ideal o fundamento da subjetividade e da cultura. Laurent aponta, ainda, que a relação ao pai não é só fundamento do sujeito, mas o traço da convergência entre as forças opostas (amor e ódio, libido e destrutividade) que marcam todos os laços do sujeito. Nesse sentido, o pai não se reduz a ser um fundamento histórico, atualizando-se em todos os traços que revelam o fundo de real de onde o sujeito se destaca. Ainda assim, o trabalho de Lacan foi o de reconstruir o percurso histórico do pai no pensamento ocidental e extrair daí o lugar da psicanálise. A evolução da família no sentido de sua redução ao núcleo pai/mãe/filhos reduz o laço social à aliança entre o homem e a mulher que devém o laço mínimo de civilização. Todavia, Lacan não atribui a esse núcleo mínimo o valor de alicerce, mas, sim, de resto, resíduo. Isto é, na evolução histórica da famí- 
lia o que resta são pai-mãe-criança como relações elementares no processo de humanização, historicamente resistentes ao desaparecimento. $\mathrm{O}$ nome da mãe está vinculado ao cuidado vital que pode particularizar um bebê humano e o nome do pai é a encarnação da íntima relação entre lei e desejo.

Laurent aponta ainda que, considerando-se a multiplicidade dos usos de um nome no contexto global da civilização, é impossível "isolar o parentesco das relações particulares que os dois sexos mantêm em uma dada civilização e a significação que eles tomam para cada um" (Laurent, 2005: 101). Nesse sentido, tanto a antropologia quanto a psicanálise parecem buscar localizar em outra articulação que não a biologia em si, ou a natureza, o ponto limite entre a multiplicidade dos nomes e o real.

O regime das alianças na civilização ocidental contemporânea é sem dúvida múltiplo, todavia o casamento e a filiação persistem. Nesse contexto se multiplicam também os debates sobre o que seja, ou onde se funda a paternidade. Debate que Lacan já antecipara ao pluralizar o Nome do pai e ao ampliar o tratamento da paternidade desde o Nome do pai até a nomeação, o pai do nome.

Centrando-nos no tema que nos ocupa neste capítulo, qual seja, a relação entre o sexo e o real, vemos que a posição que Laurent indica como sendo a da psicanálise de orientação lacaniana frente ao Nome do Pai pode ser estendida ao sexo. Laurent indica que o limite dos semblantes quanto ao real não pode ser fundado exclusivamente em perspectivas pragmáticas, sob pena de que as nomeações sejam somente produçôes ad hoc, ou produçôes de conveniência. Segundo Laurent, é preciso que o ato de nomeação retorne para quem nomeia. Laurent parece indicar aqui que a função paterna não pode ser exercida por qualquer um e a qualquer momento. Há um retorno que afeta, compromete, com seu ato, o próprio pai. É nessa via que compreendemos que o pai seja encarnado e, portanto, vivo. Laurent ressalta, no entanto, que é no fracasso, no limite da função - paterna, no caso - que se encontra a relação entre nominalismo e realismo. Uma relação que não se funda em nenhum utilitarismo, mas sim num impossível da função:

Não é possível se alinhar plenamente e de maneira satisfatória sob o nome pai porque a função faz objeção a isso. Há um impossível em jogo. [...] O nome do pai assegura sua consistência ao nomear o impossível. O relativismo sem margens pensa poder reabsorver a multiplicidade das identidades de gozo na pluralidade dos "gêneros", sem resto. Sustentamos, com Lacan, que o Nomedo-Pai marca o resíduo irredutível que assinala a impossibilidade desse empreendimento (Laurent, 2005: 105). 
O impossível se situa no nível do sexo ou, melhor, da diferença sexual. Os aforismos lacanianos - "não há relação sexual" e "não há proporção entre os sexos" - situam o impossível no plano da diferença sexual. As fórmulas da sexuação propostas por Lacan no Seminário 20 (Lacan, 1972-1973/1985: 105) indicam uma desproporção quanto ao tratamento da castração. Enquanto, na sexualidade masculina, a exceção do pai (o Um fora da castração) universaliza a castração para os homens fazendo de cada um deles um caso particular desse universal, no caso das mulheres não há exceção à castração, o que não permite a criação de nenhum universal, conseqüentemente nenhum particular também; nesse plano só existem singularidades. Assim sendo, temos dois tratamentos distintos do impossível.

É indiscutível, especialmente depois do trabalho de Michel Foucault, que a sexualidade e os corpos se interligam discursivamente. Falar de gênero ou de sexualidade fora do campo discursivo a que estão submetidos os corpos seria um equívoco (Foucault, 1997). A psicanálise também assim o considera. Não há sexualidade, ou não há sintoma, fora da cultura. Não há clínica do sujeito sem clínica da civilização. $\mathrm{O}$ corpo sexuado da era vitoriana na qual Freud inventa a psicanálise já não é o mesmo dos anos subseqüentes à virada do milênio. Nesse sentido, o valor das fantasias homoeróticas, por exemplo, numa e noutra época, é bastante diverso. Não é possível negar o efeito político da difusão na cultura da idéia de descontinuidade entre sexo biológico, gênero e sexualidade. Difusão esta que é tributária também da psicanálise (Coelho dos Santos, 2001). Entretanto, parece ter havido um apagamento da materialidade do corpo como um referente essencial na determinação da sexualidade. Parece que o fato, trazido à luz por Freud, de que o fundamento infantil da sexualidade é perverso-polimorfo autorizou uma certa desconsideração da anatomia, ainda que para ele a anatomia fosse, sim, o destino (Freud, 1905/1972).

Essa materialidade real da diferença anatômica entre os sexos localiza-se também no campo dos significantes. Observamos que para muitos analistas a diferença entre os significantes precede e prescinde da diferença anatômica. Aparentemente, eles acreditam demais na primazia do simbólico, ao ponto de cair no nominalismo, como denuncia Éric Laurent (2005).

Colete Soler (2006), por exemplo, empreende todo um esforço de não tomar a anatomia como fundamento essencial do masculino e do feminino. Considera, entretanto, que a "escolha" sexual não é arbitrária, vez que nesta escolha não há lugar para a "indiferença”, já que o significante, em última instância, está ligado à anatomia:

É um órgão do corpo que dá sua representação ao significante falo, e por isso se diz que um indivíduo é menino ou menina, antes de qualquer posição de sujei- 
to. Logo, se há uma escolha, é pelo menos uma escolha vivamente aconselhada. De outra forma, não se compreenderia a obtenção, de qualquer modo de duas metades que praticamente se superpóe à sex ratio, de tal sorte que a reprodução da espécie continua a se dar [...] Em todo caso, é certo que, como os significantes "homem" e "mulher" não deixam de se relacionar com a anatomia, o sujeito é representado a priori por um ou outro desses significantes, e não tem opção de não se pautar por eles. Portanto, persiste a questão (Soler, 2006: 226).

Que estatuto dar à materialidade do corpo no processo de identificação a uma posição sexuada? Essa materialidade deve ser tratada como um dado de realidade. A realidade funda-se em última instancia no real como impossível, que é um limite à liberdade das relações entre os significantes A sexuação é uma exigência feita ao aparelho psíquico em conseqüência de suas relações com o corpo. Esse trabalho psíquico é a elaboração do inconsciente. Neste sentido, a anatomia não é propriamente o destino, mas o fundamento da sexuação. O que haveria de mais real.

Os teóricos queer parecem preconizar que a identidade sexual ou qualquer nomeação (em especial as de "homem" ou "mulher") é sempre da ordem do excesso, isto é, não remetendo a nenhum real específico. Toda nomeação é invenção. $\mathrm{O}$ método que utilizam é a desconstrução dos semblantes identitários. Como indicam Miller e Laurent (2005), este processo desconstrutivo não exige um real. Ao contrário, valida todos os semblantes. Tal procedimento parece manter, no fundo, um ideal de sujeito "não-identificado", plástico a qualquer modo de gozo. Os autores destacam, inclusive, como o efeito deste processo tem sido, ao contrário do desejado, uma multiplicação de identidades.

\section{Para Concluir}

As cenas de rua relatadas no início deste capítulo, pelas reações que provocam, embora não possibilitem uma generalização segura, sugerem a hipótese de que as reações distintas às duas cenas se devem justamente à diferença quanto ao que rege e organiza a sexualidade masculina e a feminina. Na cena pública, o amor entre os dois homens parece revelar uma certa deposição de sua posição fálica frente ao outro sexo. Aparentemente, isso é percebido como um ato transgressivo, como se pode depreender das seguintes falas: "que pouca vergonha!" ou "é o fim do mundo". Essa conduta parece ser lida como uma abdicação de uma potência. Ao passo que no caso das mulheres não há vestígio de uma leitura pela via da transgressão. Ao contrário, as pessoas parecem reagir com uma certa complacên- 
cia com as misteriosas vias pelas quais se escoa o desejo feminino. Esse caráter misterioso pode ser lido como mais um índice da falta fálica do lado da mulher. Falta que agita e localiza, para o homem, sua potência fálica.

Quanto ao filme, como já dissemos no início, talvez seja uma demonstração de que nem todas as formas de amor valham a pena. Nem tanto pelo fracasso que implicam, já que todo amor é, em sua essência, uma forma de recobrimento do impossível da relação sexual, mas porque para cada sujeito há um destino, um sentido a dar à sua anatomia, e o gozo daí derivado não é equivalente a qualquer outro, nem tampouco se pode escrevê-lo com quaisquer letras, ou cores.

\section{REFERÊNCIAS BIBLIOGRÁFICAS}

Bauman, Z. (2004). Amor líquido. Sobre a fragilidade dos laços humanos. Rio de Janeiro: Jorge Zahar.

Coelho dos Santos, T. (2001). Quem precisa de análise hoje? O discurso analitico: novos sintomas e novos laços sociais. São Paulo: Bertrand Brasil.

Foucault, M. (1997). A história da sexualidade vol. 1. A vontade de saber. (M. T. C. Albuquerque e J. A. G. Albuquerque, Trad.). Rio de Janeiro: Graal.

Freud, S. (1905). Três ensaios sobre a sexualidade. Edição standard brasileira das obras completas de Sigmund Freud, vol. 7. Rio de Janeiro: Imago, 1972.

. (1924). A dissolução do complexo de Édipo. (J. O. A. Abreu, Trad.). Edição standard brasileira das obras completas de Sigmund Freud, vol. 19. Rio de Janeiro: Imago, 1976.

. (1924). As conseqüências psíquicas da distinção anatômica entre os sexos. Edição standard brasileira das obras completas de Sigmund Freud, vol. 19. Rio de Janeiro: Imago, 1976.

Lacan, J. (1972-1973). O seminário, Livro 20. Mais, ainda. (Magno, M. D., Trad.). Rio de Janeiro: Jorge Zahar, 1985.

(1975-1976). Le Séminaire, livre 23, Le sinthome. Paris: Éditions du Seuil, 2005.

Laurent, E. (2005). O Nome-do-Pai entre Realismo e Nominalismo. Opção Lacaniana, 44, 92-105. São Paulo: Eólia.

Louro, G. L. (2004). Um corpo estranho. Ensaios sobre sexualidade e a teoria queer. Belo Horizonte: Autêntica Editora.

Michaelis. (2006). Edição eletrônica. (http://cf.uol.com.br/michaelis/dicionar).

Miller, J. A. (1996-1997). El Otro que no existe y sus comités de ética. Seminario en colaboración con Eric Laurent. Buenos Aires: Paidós, 2005.

Psic. Clin., Rio De Janeiro, vol.18, N.2, P.109 - 123, 2006 
- (1998). Los signos del goce (pp. 228-235). Buenos Aires: Paidós.

. (2000). Os seis paradigmas do gozo. Opção Lacaniana, 26/27, 87-105. São

Paulo: Eólia.

Miller, J.-A. e Milner, D. (2004). Evaluation: entretiens sur une machine d'imposture. Paris: Agalma.

Miller, J.-A. e Laurent, E. (2005). Piéce détaché. Seminário inédito. Aula de $1^{\circ}$ de junho de 2005.

Soler, C. (2006). O que Lacan dizia das mulheres. Rio de Janeiro: Jorge Zahar.

\section{NoTAS}

1 “Os sujeitos que cruzam as fronteiras de gênero e de sexualidade talvez não 'escolham' livremente essa travessia, eles podem se ver movidos para tal por muitas razōes, podem atribuir a esse deslocamento distintos significados [...] Atravessam fronteiras ou adiam o momento de cruzá-las. Muitos permanecem referidos a via mestras, mesmo que pretendam recusá-la e 'partir para outra'... Sua recusa nem sempre é crítica, contundente ou subversiva; por caminhos transversos, sua recusa pode acabar reforçando as mesmas regras e normas que pretendeu negar" (Louro, 2004: 19).

Recebido em 23 de agosto de 2006 Aceito para publicação em 2 de novembro de 2006 